\title{
A study on stress distribution to cement layer and root dentin for post and cores made of CAD/CAM materials with different elasticity modulus in the absence of ferrule
}

\author{
Guilherme -Schmidt de Andrade ${ }^{1}$, João-Paulo-Mendes Tribst ${ }^{2}$, Amanda-Maria-de Oliveira Dal Piva ${ }^{2}$, \\ Marco-Antonio Bottino ${ }^{3}$, Alexandre-Luiz-Souto Borges ${ }^{4}$, Luiz-Felipe Valandro ${ }^{5}$, Mutlu Özcan ${ }^{6}$
}

${ }^{1}$ DDs, MSc Student in Prosthodontics, Department of Dental Materials and Proshodontics, São Paulo State University (Unesp), Institute of Science and Technology, São José dos Campos / SP, Brazil. Address: Av Engenheiro Francisco José Longo, 777, Jardim São Dimas, São José dos Campos, São Paulo, Brazil

${ }^{2}$ DDs, MSc, PhD Student, Department of Dental Materials and Proshodontics, São Paulo State University (Unesp), Institute of Science and Technology, São José dos Campos / SP, Brazil. Address: Av Engenheiro Francisco José Longo, 777, Jardim São Dimas, São José dos Campos, São Paulo, Brazil

${ }^{3}$ DDs, MSc, PhD, Professor, Department of Dental Materials and Proshodontics, São Paulo State University (Unesp), Institute of Science and Technology, São José dos Campos / SP, Brazil. Address: Av Engenheiro Francisco José Longo, 777, Jardim São Dimas, São José dos Campos, São Paulo, Brazil

${ }^{4}$ DDs, MSc, PhD, Adjunct Professor, Department of Dental Materials and Proshodontics, São Paulo State University (Unesp), Institute of Science and Technology, São José dos Campos / SP, Brazil. Address: Av Engenheiro Francisco José Longo, 777, Jardim São Dimas, São José dos Campos, São Paulo, Brazil

${ }_{5}^{5}$ DDs, MSc, PhD, Professor, Federal University of Santa Maria, Prosthodontic Unit, Faculty of Odontology, Santa Maria, Rio Grande do Sul State, Brazil

${ }^{6}$ DDs, MSc, PhD, Professor, University of Zurich, Dental Materials Unit, Center for Dental and Oral Medicine, Clinic for Fixed and Removable Prosthodontics and Dental Materials Science, Zurich, Switzerland

Correspondence:

Av Engenheiro Francisco José Longo, 777

Jardim São Dimas, São José dos Campos

São Paulo, Brazil. CEP 12245-000

amodalpiva@gmail.com

de Andrade GS, Tribst JPM, Dal Piva AMO, Bottino MA, Borges ALS, Valandro LF, Özcan M. A study on stress distribution to cement layer and root dentin for post and cores made of CAD/CAM materials with different elasticity modulus in the absence of ferrule. J Clin Exp Dent. 2019;11(1):e1-8. http://www.medicinaoral.com/odo/volumenes/v11i1/jcedv11i1p1.pdf

Received: $12 / 09 / 2018$ Accepted: 17/12/2018

\begin{abstract}
Backgound: To evaluate the stress distribution in a maxillary central incisor with different post and cores made of six CAD/CAM materials with different elastic modulus in the absence of ferrule using the finite element analysis. Material and Methods: A three-dimensional endodontically treated maxillary central incisor restored with an all-ceramic crown was modelled in Rhinoceros (5.0 SR8, McNeel). The geometries were analyzed in ANSYS 17.2 (ANSYS Inc.) considering isotropic, homogeneous, linearly elastic materials with perfectly bonded contacts. The elastic moduli (E) of the post-and-cores defined the groups to be compared: nanoceramic resin $(\mathrm{E}=12.8 \mathrm{GPa})$; composite resin $(\mathrm{E}=16 \mathrm{GPa})$; hybrid ceramic $(\mathrm{E}=34.7 \mathrm{GPa})$; lithium disilicate $(\mathrm{E}=95 \mathrm{GPa})$; titanium (Ti-Al6-V4) $(\mathrm{E}=112 \mathrm{GPa})$; and Y-TZP material $(\mathrm{E}=209.3 \mathrm{GPa})$. The set was constrained in the cortical bone and loaded $\left(45^{\circ} / 100\right.$ $\mathrm{N})$ on the incisor palatine face. Stress distribution was analyzed by Maximum Principal Stress criteria for the crown-core cement line, Post-and-core's cement line, Post-and-core system and Dentin.
\end{abstract}


Results: The stress distribution at the crown-core cement line (11.4 - 13.2 MPa) was inversely proportional to the increase of the elastic modulus of the post-core approaches, while it was direct proportional on the post-and-core (4.7-40 $\mathrm{MPa}$ ) and cement line (4.1 - 6.2 MPa). Stress distribution on the dentin was similar for all groups (24.7 - 25.3 MPa). Conclusions: Post-and-core made by CAD/CAM seems to be an efficient treatment alternative, since it is a conservative approach, promotes better aesthetic quality and it allows the control of the cement line thickness.

Key words: Endodontically treated teeth, Post-and-core technique, Ceramic crown, Finite element analysis, Biomimetics.

\section{Introduction}

Posts are normally used to provide retention to the core in endodontically treated teeth with extensive loss of coronal and intracanal structures. In these cases, cast post and cores in gold alloys have been considered the gold standard due to their excellent success rate, favorable long-term prognosis and ease of manufacturing (1).

However, there is a concern as to how much the core color would affect the aesthetic outcome of the final restoration (2), since over the years the use of all-ceramic restorations has been extensively increasing, and a plausible consequence might be the oxidation effect of some metallic alloys over the gingival margin in a thin periodontium (3).

Thus, prefabricated resin-reinforced glass fiber posts associated with direct composite resin cores have been used as an aesthetic alternative when restoring anterior teeth (4). It is argued that these posts have an elastic modulus closer to the dentin, which provides a uniform stress distribution on the post/cement/dentin interfaces and on the dental remnant structure under masticatory intermittent loading, thus minimizing the risk of catastrophic root fracture (5). However, the prefabricated posts associated with direct cores when exposed to the clinical intermittent cyclic loading are subject to gaps or debonding of the post/core interface, increasing the failure potential of this system over the clinical service (for instance, loss of retention of the assembly) (6). Because they are prefabricated, such posts might not adequately adapt to the anatomy or specific conditions of root canals (oval shape, flared roots), resulting in a larger cement line which might cause an increase in the risk of loss of post retention $(7,8)$. The thickness of the resin cement that shows the best stress distribution is up to 0.3 $\mathrm{mm}$ (7). On the other hand, customized post and cores could be an option for canals in which a prefabricated post could not adapt properly (reduction of cement's thickness).

The evolution of CAD/CAM systems and the availability of ceramic blocks with superior aesthetic characteristics such as translucency and color gradient allow the preparation of monolithic restorations with a satisfactory aesthetic result. The industrial processing of these ceramic blocks results in higher structural reliability (reduction of defects population into the material bulk) (9).
In addition, it is known that the fracture strength and fatigue resistance of all-ceramic restorations is increased when adhesively luted in a susceptible substrate (10), which does not occur under cast metal cores since these materials have low adhesive characteristics.

Currently CAD/CAM systems allow machining of a wide range of dental materials, such as the glass-ceramics (feldspathic, leucite-reinforced feldspar, and lithium disilicate), laboratory resins, yttria stabilized zirconia, metals, and more recently the polymer infiltrated ceramic (PIC material) or also known as hybrid ceramics (9). This allows the clinician to choose the best material according to the need of each clinical case (11). In addition, these systems allow the restoration to be designed by a particular software, which gives the dentist better control of the characteristics of the restorations, such as controlling the thickness, shape, marginal features, occlusion of the restoration, as well as, thickness of the resin cement.

In terms of root restoration, that restoring approach permit to control the resin cement's thickness when restoring oval root canals and flared canals, different from inherent circumstances for pre-fabricated post (thicker resin cement), which might influence the stress distribution on the restorative assembly. Besides, materials with distinct elastic modulus milled by CAD/CAM system might affect the stress distribution on root/assembly, influencing the clinical performance overtime.

Thus, this current study aimed to assess the stress distribution (biomechanical behavior) in a maxillary central incisor with different post and cores made of six CAD/ CAM materials with different elastic modulus through finite element analysis. The null hypotheses tested were that the elastic modulus of the material does not affect stress distribution at the: 1) cement line between the full crown and the core build-up; 2) cement line between the post and the root; 3) post; or 4) remaining dentin.

\section{Material and Methods}

-Finite Element analysis for pre-processing The 3D model used in a previous study (7) composed of periodontal ligament and cortical bone with an 0.3 and $0.5 \mathrm{~mm}$ thickness, respectively, medullary bone, gutta percha with length of $4 \mathrm{~mm}$, post and core, all-ceramic crown of lithium disilicate (e.max CAD, Ivoclar Viva- 
dent, Schaan, Liechtenstein), and dentin were prepared for full-crown without ferrule. Both the crown and the post and core were cemented with a $0.3 \mathrm{~mm}$ (Fig. 1) line of resin cement Panavia F (Kuraray, Tokyo, Japan).

-Finite element analysis for processing

The geometries were imported in STEP format to Computer Aided Engineering (CAE) software (ANSYS 17.2, ANSYS Inc.), where meshes were generated through the convergence test until obtaining a number of nodes $(382,383)$ and elements $(215,828)$ unable to interfere with the study outcome (Fig. 1A). The materials were was applied to the central region of the palatine face (Fig. 1B), with the system fixated at the cortical bone base. In this study, the stress distribution was analyzed by the Maximum Principal Stress criteria.

-Analysis

The data obtained from the stress distribution at the cement line between crown and core, between post and root dentin, post and dentin were analyzed qualitatively and quantitatively through graphs and tables using the $10 \%$ confidence limit established by the mesh convergence test. The maximum stresses were compared with

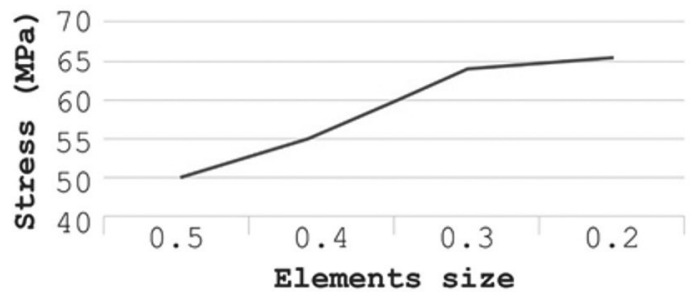

A oblique force $\left(45^{\circ}\right)$ on palatal surface. The red square shows the point of load application.

considered isotropic, homogeneous and linearly elastic with perfectly bonded contacts. The groups were divided according to the elastic modulus of the materials used for restoring the post-and-core (Table 1) (12-17): Nanoceramic resin (Lava Ultimate, 3M ESPE, St. Paul, MN, USA); composite resin (Paradigm MZ10, 3M ESPE); hybrid ceramic (Enamic, VITA Zahnfabrik, Bad Säckingen, BW, Germany); lithium disilicate (e-max CAD, Ivoclar Vivadent); titanium (Ti-Al6-V4) and tetragonal zirconia polycrystalline stabilized by yttria (Y-TZP, VITA Zahnfabrik). An oblique (45 ) load of 100 N(7) data from laboratory tests already published in the literature.

\section{Results}

Table 2 shows the maximum tensile stress peaks in each region obtained for all groups. Maximum Principal Stress (MPS) analysis demonstrated that higher stress concentration in the cement line between crown-core when a post and core with lower elastic modulus was used (Fig. 2A). On the other hand, stiffer post and core showed more stress concentration in the cement line

Table 1: Properties of materials used in models.

\begin{tabular}{|c|c|c|}
\hline Material & Elastic Modulus (GPa) & Poisson Ratio \\
\hline Dentin (12) & 18.6 & 0.31 \\
\hline Periodontal ligament (12) & 0.0689 & 0.45 \\
\hline Medullar bone (12) & 1.37 & 0.30 \\
\hline Cortical bone (12) & 13.7 & 0.30 \\
\hline Luting agent (13,14) & 7.5 & 0.23 \\
\hline Nanoceramic resin (15) & 12.8 & 0.30 \\
\hline Composite resin (14) & 16.0 & 0.30 \\
\hline Hybrid ceramic (16) & 34.7 & 0.28 \\
\hline Lithium disilicate (14) & 95.0 & 0.30 \\
\hline Titanium alloy (17) & 112 & 0.33 \\
\hline Zirconia Y-TZP (17) & 209.3 & 0.32 \\
\hline
\end{tabular}


Table 2: Maximum tensile stress peaks (MPa) in each region obtained for all groups.

\begin{tabular}{|c|c|c|c|c|}
\hline Post-and-core material & Crown's cement line & Post-and-core's cement line & Post-and-core system & Dentin \\
\hline Nanoceramic resin & 13.2 & 4.1 & 4.7 & 24.9 \\
\hline Composite resin & 12.7 & 4.3 & 5.3 & 25.3 \\
\hline Hybrid ceramic & 12.2 & 4.3 & 10.8 & 25.1 \\
\hline Lithium disilicate & 11.4 & 6 & 34.2 & 25.3 \\
\hline Titanium alloy & 11.4 & 6 & 40 & 24.8 \\
\hline Zirconia Y-TZP & 11.4 & 6.2 & 70 & 24.7 \\
\hline
\end{tabular}

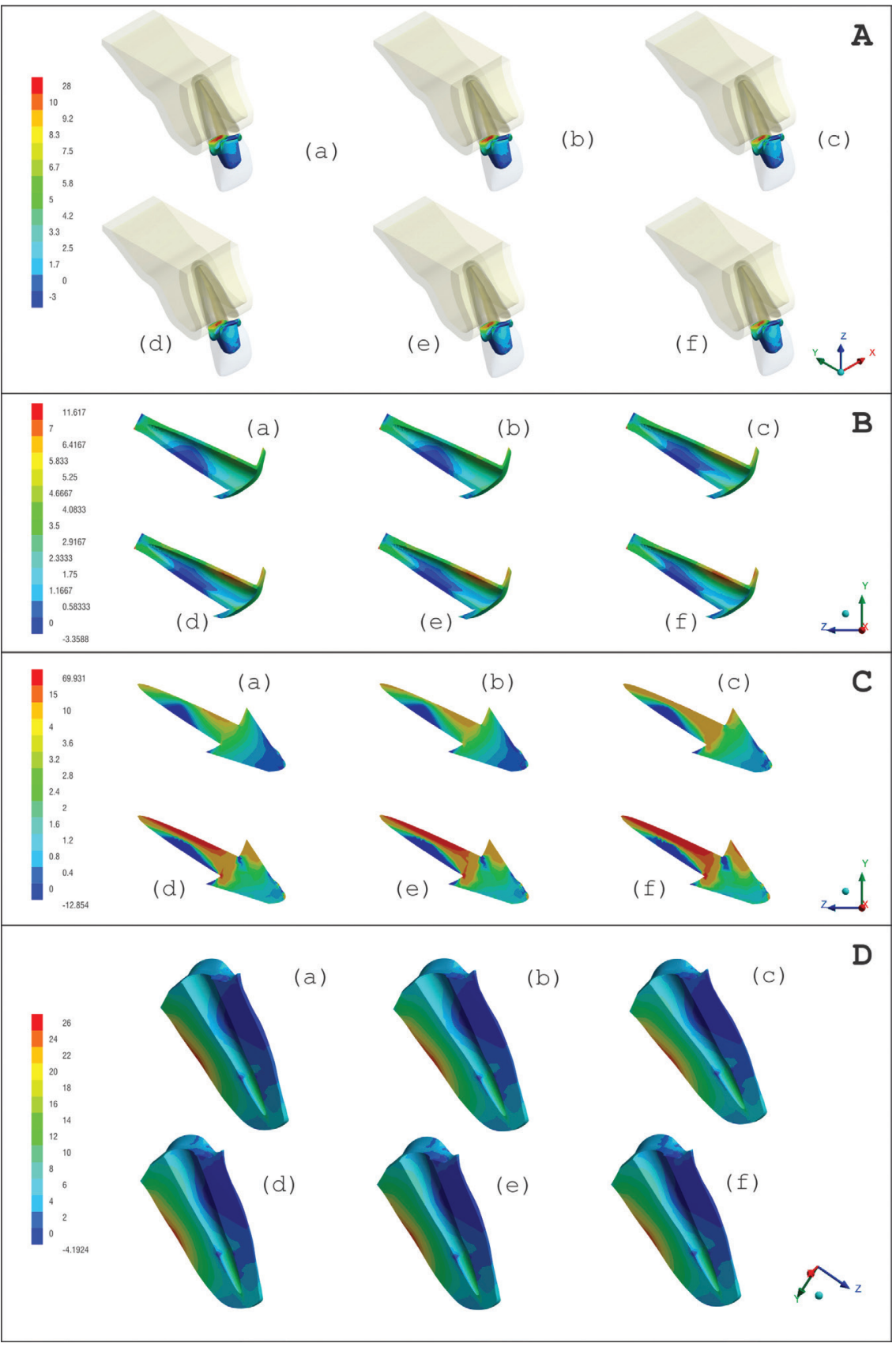

Fig. 2: MPS distribution on the A) cement line between crown-core, B) cement line between post and root dentin, C) post-and-core and D) in dentin according to restorative materials: a) Nanoceramic resin, b) Composite resin, c) Hybrid ceramic, d) Lithium disilicate, e) Titanium, f) Zirconia Y-TZP. 
between post and dentin (Fig. 2B). However, the difference between groups was only $2 \mathrm{MPa}$ for the crown/ core and post/dentin cement lines. More homogeneous distribution (tensile stress) in the post area was observed when using materials with elastic modulus closer to dentin (nanoceramic resin and composite resin) (Fig. 2C). Regardless of post-and-core material, stress distribution in dentin was similar for all groups (Fig. 2D). Figure 3 shows a linear graph of the tensile stress concentration versus the elastic modulus of the post and core, corroborating that the higher the elastic modulus of the post and core the higher the stress concentration on its structure. demonstrated that the maximum tensile stress difference between the less and more rigid material was approximately $2 \mathrm{MPa}$ (Table 2), and did not show a significant difference for the bond strength of the crown. However, this stress would possibly be relevant when the individual bond strength of each material were taken into account. In this sense, the results show that the maximum stress distribution exceeded the bond strength (Table 3) $(10,22-29)$ of zirconia with surface treatment $(7.9 \pm 2.6$ $\mathrm{MPa}$ (26), and was close to the resistance of titanium $(14.79 \pm 2.33 \mathrm{MPa})(27)$ and the nanoceramic resin $(14.35 \pm 2.56)(25)$.

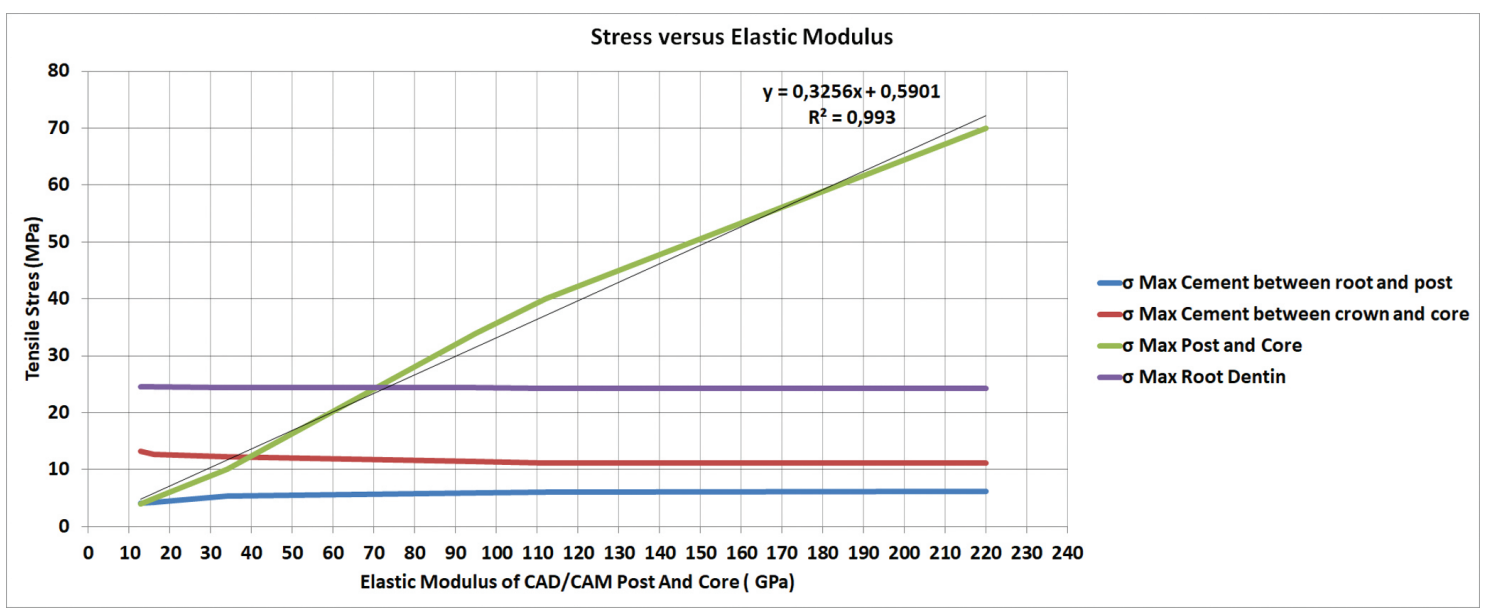

Fig. 3: Line graph of the variation according to the tensile stress concentration as a function of the elastic modulus of the post and core.

\section{Discussion}

The characteristics of the interfaces and the rigidity of the materials strongly influence the biomechanical behavior of teeth treated with post and cores (14). In addition, failure modes observed in the oral cavity usually occur during functional or parafunctional cyclic loads, repeated over a long period of time; failures by maximum stress would occur in situations such as dental trauma or during removal of temporary crowns (18). Even though finite element analysis is a static and linear analysis, this computational study can predict specific results, including mechanical behavior of the materials (19), mainly because fatigue failures begin in areas of stress concentration (20).

The first hypothesis was rejected, since the results showed a higher stress concentration in the crown cementation line when using post-and-core technique with lower elastic modulus (Fig. 2A). As in the study by Kelly et al. (21) and Dejak and Młotkowski (22), ceramics cemented under rigid substrates such as cast metal cores exhibit longer survival time and lower failure rate because the tensile stress concentration is lower than those cemented in dentin. However, our current study
Moreover, the our results showed that lower elastic modulus material generates lower concentration stress at the cement line between the post and dentin, compared with a post-and-core system made with more rigid materials (Fig. 2B), thus rejecting the second hypothesis. The lowest stress concentrations were in the posts made of nanoceramic resin, hybrid ceramic and composite resin (Table 2). Therefore, restorative materials with low and unstable resin bond strength might have a higher displacement risk failure. As it is already known, the high $\mathrm{C}$ factor, presence of humidity, lower light penetration of the curing lights, access to intracanal dentin walls for adhesion procedures make the adhesion to root dentin difficult (30).

An accumulation of flaws combined with cyclic loads concentrates stresses at the adhesive interfaces, thus causing fatigue in the materials even if the forces do not reach the tensile limit (31). Bottino et al. (32) demonstrated that after mechanical cycling, zirconia posts cemented with resin luting agents had their bond strength decreased in root dentin. This probably occurred due to the high elastic modulus of the material that generates a higher stress concentration in the cementation line, in 
Table 3: Mean values of bond strength (MPa) between resin cement and post-and-core material and mean values of flexural strength (MPa) of each material used in the study.

\begin{tabular}{|c|c|c|}
\hline Post-and-core material & Bond Strength (MPa) & Flexural Strength (MPa) \\
\hline Nanoceramic resin & $14.35 \pm 2.56(25)$ & $189.7 \pm 28.2(11)$ \\
\hline Composite resin & $30.7 \pm 8.6(23)$ & $248.4 \pm 24.5(25)$ \\
\hline Hybrid ceramic & $22.21 \pm 3.04(25)$ & $202.1 \pm 17.9(11)$ \\
\hline Lithium disilicate & $17.1 \pm 15.3(24)$ & $376.9 \pm 76.2(11)$ \\
\hline Titanium alloy & $14.79 \pm 2.33(27)$ & $1906.3 \pm 389.3(28)$ \\
\hline Zirconia Y-TZP & $13.9 \pm 11.02(26)$ & $861 \pm 92(29)$ \\
\hline Dentin & & $105.5(22)$ \\
\hline
\end{tabular}

addition to the lower adhesive strength of the polycrystalline zirconia, which increased the fatigue risk at the interface during the load incidence. In contrast, less rigid materials would suffer less fatigue effect on their bond strength, since the stress distribution at this interface is more homogeneous (30), so we could assume that posts with smaller elastic modulus would have less displacement risk.

The third null hypotheses was rejected in this study, because the stress distribution in the post was inversely proportional as the elastic modulus of the materials increased (Fig. 2C; Fig. 3) (more rigid material generated 15 times higher stress) (Table 2). The systems made of zirconia and titanium had the highest stress concentration at the post, with a maximum tensile stress concentration of 40 and $70 \mathrm{MPa}$, respectively (Table 2). However, the stress peak would not reach the flexural strength of these materials $(28,29)$ (Table 3 ), therefore, failure by post fracture would not be expected. Another material that obtained higher values of stress concentration was lithium disilicate with around $34 \mathrm{MPa}$ (Table 2), lower than its flexural strength, around $376 \mathrm{MPa}$ (11) (Table 3). However, it is important to highlight the fact that ceramic materials fail in the oral environment with lower loads than those obtained through fatigue resistance tests (10). The complex combination of cyclic loads, the presence of water and the alternation of thermal and chemical conditions in the oral environment result in a decrease in the resistance of the ceramics, leading to failure (21). Also, damages can be intensified using the sliding contact during load application $(32,33)$. This can be attributed to different microstructures, meaning the variation of the ratio between glassy and crystalline phase strongly influences the propagation of cracking and its mechanical properties. Because lithium disilicate is composed of a glassy phase, it has a higher risk of failure when compared to a polycrystalline ceramic such as zirconia (34), suggesting that it would not be suitable for making intrarradicular post-systems even with lower tensile stress concentration (Fig. 2C,D).

A new class of dental material was evaluated in this study: a polymer-infiltrated ceramic (hybrid ceramic) with a microstructure containing $86 \%$ (by weight) porous feldspar ceramic matrix infiltrated with a copolymer (urethane dimethacrylate and triethylene glycol dimethacrylate) (16). Although there was no studies indicating or having performed a post-and-core system with this material, we observed that the maximum tensile stress at the post was $10 \mathrm{MPa}$, while the flexural strength value of this material in a laboratorial study was 202 MPa (11) (Table 3), so it can be assumed that the material would not fracture. Even though hybrid ceramics have a high glass matrix content, which under fatigue would increase the risk of failure, this new material has a mechanism that limits the crack propagation due to the presence of the two phases (35). Therefore, the material in our study would have potential for use in one-piece cast-and-post system.

Finally, the fourth null hypothesis was not rejected because the tensile stress distribution in dentin was similar for all the type of materials (Fig. 2D; Table 2), not reaching the flexural strength of dentin (Table 3). This probably occurred because the luting agent has an elastic modulus similar to dentin, and this layer between the dentine and the post would reduce the stress concentration in the dentin (19). Less rigid posts allow the teeth to bend when subjected to loads, providing better stress distribution at the post/cement/dentin interface (36). This can influence the failure mode of the weakened remnant. A laboratorial study (37) observed that endodontically treated teeth restored with zirconia posts systems had higher rates of catastrophic failure. In that study, less rigid posts such as fiberglass posts showed adhesive failure before the occurrence of root/post/core fracture. This may be positive for the remaining tooth, since failure of the post prior to the remnant would preserve the teeth from catastrophic failure, but it can compromise the prosthetic assembly.

Although the finite element analysis is a reliable method to predict potential failures (19), the limitation of this method is that the materials and structures are considered linearly elastic and homogeneous, which does not occur in real conditions. Also, the mean masticatory load in anterior region can vary (per exemple from $93 \mathrm{~N}$ to 
$206 \mathrm{~N})(38)$ according to gender (38-40), age (39), race (38), cranio-facial morphology, periodontal support of teeth, temporomandibular disorders and pain (41), weight and height (40) and dental absence $(40,42)$. In addition, as already discussed, failure in an oral environment normally occurs due to fatigue and slow crack growing (20). Therefore, in order to evaluate the behavior of these materials under fatigue, more laboratory and clinical studies should be conducted to better predict the success of these new treatment proposals evaluated by this current investigation.

From this study, the following can be concluded:

The elastic modulus of the post and cores made by CAD/ CAM facility are directly proportional to the concentration of deleterious stress in its own structure. Thus, it suggests a better prognosis of stress distribution to the luting cement and the root dentin with the use of materials with lower elastic modulus.

\section{References}

1. Creugers NH, Mentink AG, Käyser AF. An analysis of durability data on post and core restorations. J Dent. 1993;21:281-4.

2. Bittner N, Hill T, Randi A. Evaluation of a one-piece milled zirconia post and core with different post-and-core systems: An in vitro study. J Prosthet Dent. 2010;103:369-79.

3. Michalakis KX, Hirayama H, Sfolkos J, Sfolkos K. Light transmission of posts and cores used for the anterior esthetic region. Int J Periodontics Restorative Dent. 2004;24:462-9.

4. Ambica K, Mahendran K, Talwar S, Verma M, Padmini G, Periasamy R. Comparative evaluation of fracture resistance under static and fatigue loading of endodontically treated teeth restored with carbon fiber posts, glass fiber posts, and an experimental dentin post system: an in vitro study. J Endod. 2013;39:96-0.

5. Silva GR, Santos-Filho PC, Simamoto-Júnior PC, Martins LR, Mota AS, Soares CJ. Effect of post type and restorative techniques on the strain and fracture resistance of flared incisor roots. Braz Dent J. 2011;22:230-7

6. Fernandes AS, Shetty S, Coutinho I. Factors determining post selection: a literature review. J Prosthet Dent. 2003;90:556-62.

7. Dal Piva AMO, Tribst JPM, Souza ROAE, Borges ALS. Influence of alveolar bone loss and cement layer thickness on the biomechanical behavior of endodontically treated maxillary incisors: A 3-dimensional Finite Element Analysis. J Endod. 2017;43:791-5.

8. Souza RO, Alves ML, De Sousa RS, Dal Piva AM, Gondim LD, Ribeiro IL, et al. Resin bonding to root dentin: influence of the alveolar bone level and thickness of the cement layer. Minerva Stomatol. 2014;63:239-48.

9. Beuer F, Schweiger J, Edelhoff D. Digital dentistry: an overview of recent developments for $\mathrm{CAD} / \mathrm{CAM}$ generated restorations. $\mathrm{Br}$ Dent J. 2008;204:505-11.

10. Kelly JR, Benetti P. Ceramic materials in dentistry: historical evolution and current practice. Aust Dent J. 2011;56:84-96.

11. Lawson NC, Bansal R, Burgess JO. Wear, strength, modulus and hardness of $\mathrm{CAD} / \mathrm{CAM}$ restorative materials. Dent Mater. 2016;32:e275-83.

12. Holmes DC, Diaz-Arnold AM, Leary JM. Influence of post dimension on stress distribution in dentin. J Prosthet Dent. 1996;75:140-7.

13. Nakamura T, Wakabayashi K, Kinuta S, Nishida H, Miyamae M, Yatani H. Mechanical properties of new self-adhesive resin-based cement. J Prosthodont Res. 2010;54:59-64.

14. Zarone F, Sorrentino R, Apicella D, Valentino B, Ferrari M, Aversa $\mathrm{R}$, et al. Evaluation of the biomechanical behavior of maxillary central incisors restored by means of endocrowns compared to a natural tooth: a 3D static linear finite elements analysis. Dent Mater. 2006;22:1035-44.
15. Chen C, Trindade FZ, de Jager N, Kleverlaan CJ, Feilzer AJ. The fracture resistance of a CAD/CAM Resin Nano Ceramic (RNC) and a CAD ceramic at different thicknesses. Dent Mater. 2014;30:954-62.

16. Ramos Nde C, Campos TM, Paz IS, Machado JP, Bottino MA, Cesar PF, et al. Microstructure characterization and SCG of newly engineered dental ceramics. Dent Mater. 2016;32:870-8.

17. Toparli M. Stress analysis in a post-restored tooth utilizing the finite element method. J Oral Rehabil. 2003;30:470-6.

18. Dietschi D, Duc O, Krejci I, Sadan A. Biomechanical considerations for the restoration of endodontically treated teeth: a systematic review of the literature--Part 1. Composition and micro- and macrostructure alterations. Quintessence Int. 2007;38:733-43.

19. Kainose K, Nakajima M, Foxton R, Wakabayashi N, Tagami J. Stress distribution in root filled teeth restored with various post and core techniques: effect of post length and crown height. Int Endod J. 2015;48:1023-32.

20. Schatz D, Alfter G, Göz G. Fracture resistance of human incisors and premolars: morphological and patho-anatomical factors. Dent Traumatol. 2001;17:167-73

21. Kelly JR, Rungruanganunt P, Hunter B, Vailati F. Development of a clinically validated bulk failure test for ceramic crowns. J Prosthet Dent. 2010;104:228-38.

22. Dejak B, Młotkowski A. Finite element analysis of strength and adhesion of cast posts compared to glass fiber-reinforced composite resin posts in anterior teeth. J Prosthet Dent. 2011;105:115-26.

23. Elsaka SE. Bond strength of novel CAD/CAM restorative materials to self-adhesive resin cement: the effect of surface treatments. J Adhes Dent. 2014;16:531-40.

24. Goracci C, Cury AH, Cantoro A, Papacchini F, Tay FR, Ferrari M. Microtensile bond strength and interfacial properties of self-etching and self-adhesive resin cements used to lute composite onlays under different seating forces. J Adhes Dent. 2006;8:327-35.

25. Marocho SM, Ozcan M, Amaral R, Bottino MA, Valandro LF. Effect of resin cement type on the microtensile bond strength to lithium disilicate ceramic and dentin using different test assemblies. J Adhes Dent. 2013;15:361-8.

26. Lung CY, Liu D, Matinlinna JP. Surface treatment of titanium by a polydimethylsiloxane coating on bond strength of resin to titanium. J Mech Behav Biomed Mater. 20151:168-76.

27. Júnior PCS, Novais VR, Machado AR, Soares CJ, Raposo LHA. Effect of joint design and welding type on the flexural strength and weld penetration of Ti-6Al-4V alloy bars. J Prosthet Dent. 2015;113:467-74.

28. Vanderlei A, Bottino MA, Valandro LF. Evaluation of resin bond strength to yttria-stabilized tetragonal zirconia and framework marginal fit: comparison of different surface conditionings. Oper Dent. 2014;39:50-63.

29. Borba M, de Araújo MD, de Lima E, Yoshimura HN, Cesar PF, Griggs JA, et al. Flexural strength and failure modes of layered ceramic structures. Dent Mater. 2011;27:1259-66.

30. Ferrari M, Mannocci F, Vichi A, Cagidiaco MC, Mjör IA. Bonding to root canal: structural characteristics of the substrate. Am J Dent. 2000;13:255-60.

31. Belli R, Baratieri LN, Braem M, Petschelt A, Lohbauer U. Tensile and bending fatigue of the adhesive interface to dentin. Dent Mater. 2010;26:1157-65.

32. Bottino MA, Baldissara P, Valandro LF, Galhano GA, Scotti R. Effects of mechanical cycling on the bonding of zirconia and fiber posts to human root dentin. J Adhes Dent. 2007;9:327-31.

33. Rekow ED, Silva NR, Coelho PG, Zhang Y, Guess P, Thompson VP. Performance of dental ceramics: challenges for improvements. J Dent Res. 2011;90:937-52.

34. Bonfante EA, Coelho PG, Guess PC, Thompson VP, Silva NR. Fatigue and damage accumulation of veneer porcelain pressed on Y-TZP. J Dent. 2010;38:318-24.

35. Gonzaga CC, Cesar PF, Miranda WG Jr, Yoshimura HN. Slow crack growth and reliability of dental ceramics. Dent Mater. 2011;27:394-06. 36. Coldea A, Swain MV, Thiel N. Mechanical properties of polymer-infiltrated-ceramic-network materials. Dent Mater. 2013;29:419-26. 
37. Al-Omiri MK, Rayyan MR, Abu-Hammad O. Stress analysis of endodontically treated teeth restored with post-retained crowns: A finite element analysis study. J Am Dent Assoc. 2011;142:289-300.

38. Kaya BM, Ergun G. The effect of post length and core material on root fracture with respect to different post materials. Acta Odontol Scand. 2013;71:1063-70.

39. Regalo SC, Santos CM, Vitti M, Regalo CA, de Vasconcelos PB, Mestriner W Jr, et al. Evaluation of molar and incisor bite force in indigenous compared with white population in Brazil. Arch Oral Biol. 2008;53:282-6.

40. Garner LD, Kotwal NS. Correlation study of incisive biting forces with age, sex, and anterior occlusion. J Dent Res. 1973;52:698-02.

41. Quiudini PR Jr, Pozza DH, Pinto ADS, de Arruda MF, Guimarães AS. Differences in bite force between dolichofacial and brachyfacial individuals: Side of mastication, gender, weight and height. J Prosthodont Res. 2017;61:283-9.

42. Koc D, Dogan A, Bek B. Bite force and influential factors on bite force measurements: a literature review. Eur J Dent. 2010;4:223-32.

43. Rosa LB, Semprini M, Siéssere S, Hallak JE, Pagnano VO, Regalo SC. Correlation between bite force and electromyographic activity in dentate and partially edentulous individuals. Electromyogr Clin Neurophysiol. 2009;49:291-7.

Acknowledgments

None.

\section{Conflict of interest}

The authors have declared that no conflict of interest exist. 